Revista de Derecho

Universidad Católica del Norte

Sección: Ensayos

Año 18 - No 2, 2011

pp. $275-304$

\title{
LA UNIFICACIÓN DE JURISPRUDENCIA PRETENDIDA POR EL RECURSO EXTRAORDINARIO. VENTAJAS Y PROBLEMAS
}

\author{
JORDI DELGado CASTRO* \\ L. IVÁN DíAZ GARCÍA**
}

Resumen: El proyecto de Código Procesal Civil en actual tramitación en el Congreso Nacional de Chile incluye una singular innovación en el ámbito recursivo. Se trata del recurso extraordinario, cuya finalidad es, en esencia, unificar la jurisprudencia en materia civil. Esta pretensión presenta indudables ventajas asociadas a la igualdad en la aplicación de la ley, a la seguridad jurídica, a reducción de costes económicos y a la legitimidad del Poder Judicial. Sin embargo, y al mismo tiempo, el cumplimiento de su finalidad unificadora se encontrará con obstáculos insalvables si mantiene el diseńo normativo con que actualmente cuenta. Tales obstáculos se relacionan con una determinada concepción y con una determinada práctica del Derecho en la familia europeo-continental en general y en el ámbito jurídico chileno en particular.

PALABRAS CLAVE: Proceso civil - reforma procesal - recursos procesales - recurso extraordinario - unificación de jurisprudencia.

\section{THE UNIFICATION OF JURISPRUDENCE ALLEGED BY AN EXTRAORDINARY REMEDY. ADVANTAGES AND PROBLEMS}

ABSTRACT: The draft of the Civil Procedure Code which is in revision in the Chilean National Congress contains a unique innovation in the recursive scope. This is an extraordinary remedy whose purpose is, in essence, to unify the civil jurisprudence. This claim presents clear advantages associated with the equal application of the law, legal certainty, reducing economic costs and the legitimacy of the judiciary. However, while fulfilling its unifying purposes, it will encounter insurmountable obstacles if it is kept the current policy. These

\footnotetext{
* $\quad$ Doctor en Derecho. Académico de la Facultad de Ciencias Jurídicas de la Universidad Católica de Temuco. Correo electrónico: jdelgado@uct.cl

** Doctor en Derecho. Académico de la Facultad de Ciencias Jurídicas de la Universidad Católica de Temuco. Correo electrónico: ivandiaz@uct.cl

Fecha de recepción: 7 de junio de 2011.

Fecha de aceptación: 20 de agosto de 2011.
} 
obstacles are related to a specific concept and a particular practice of law in continental- European family and in the legal Chilean field in particular.

KEY WORDS: Civil Proceedings - Procedural reform - Procedural remedies - Extraordinary remedy - Unification of jurisprudence.

\section{InTROducción: Planteamiento DEL PROBlema Y PREguntas DE INVESTIGACIÓN}

Mediante mensaje presidencial 398-357, de 18 de mayo de 2009, el Gobierno de Chile envió al Congreso Nacional un proyecto de ley por el que aprueba el nuevo Código Procesal Civil. En la presentación del proyecto se anuncia que en el articulado se incluye lo que constituye el mayor cambio en materia de recursos procesales: el recurso extraordinario. Inmediatamente se precisa que dicho recurso "tendrá por objeto que la Corte Suprema unifique la jurisprudencia con ocasión de una sentencia notoriamente injusta para el recurrente" y "revocar la sentencia impugnada si se han vulnerado sustancialmente garantias constitucionales" 1 .

En lo que se refiere al primero de esos objetos, que es el que centralmente interesa a los fines de este trabajo, el artículo 354 del proyecto de Código Procesal Civil dispone que la unificación de jurisprudencia procederá cuando la sentencia recurrida se oponga a la jurisprudencia uniforme, cuando la jurisprudencia previa fuere contradictoria entre sí, cuando no existiere jurisprudencia sobre la materia y cuando nuevos contextos históricos, sociales o culturales justifiquen variar la tendencia jurisprudencial.

Considerando esta pretensión unificadora, el recurso extraordinario no es un simple cambio de denominación del recurso de casación. En este sentido el presente trabajo admite como punto de partida que se trata, como ha dicho Jordi Delgado, de un recurso "con un cariz anglosajón desconocido para nuestro entorno jurídico-cultural" 2 . Y ello porque coincide con el recurso de unificación de jurisprudencia laboral en orden a "uniformar criterios e interpretaciones y sentar un precedente para que los tribunales inferiores y las propias partes al momento de presentar sus

\footnotetext{
En adelante cada vez que se haga referencia al recurso extraordinario y al articulado en el que el mismo se regula, se debe entender que se alude al referido mensaje presidencial.

Delgado Castro, Jordi (2009). "La historia de la casación civil española: una experiencia que aconseja no avanzar en el modelo de unificación de la doctrina". Revista de Derecho de la Pontificia Universidad Católica de Valparaíso, XXXIII, p. 347.
} 
demandas, tengan a la vista la opinión de la Corte Suprema frente a una determinada materia" 3 .

En el marco de la noción de precedente que subyace a la pretensión unificadora del recurso extraordinario y la evidente ajenidad de la misma en el contexto de la familia europeo continental a la que pertenece Chile, diversas son las interrogantes que se plantean. Dos de ellas interesan en el presente trabajo. La primera puede ser expresada del siguiente modo: ¿son relevantes las ventajas derivadas de la unificación de jurisprudencia pretendida por el recurso extraordinario? La segunda es del siguiente tenor: ¿son relevantes los problemas asociados a la aplicación de la unificación de jurisprudencia pretendida por el recurso extraordinario?

\section{IMPORTANCIA DEL PROBLEMA DE INVESTIGACIÓN}

Como puede suponerse, la importancia de las preguntas planteadas en este trabajo se relaciona con las posibles respuestas a que se arribe. Al respecto, y simplificando al extremo las opciones, tales respuestas pueden conducir a enfrentar básicamente cuatro escenarios.

En efecto, si las ventajas de la unificación de jurisprudencia pretendida por el recurso extraordinario son relevantes y los problemas asociados a su aplicación no son relevantes, entonces se debe mantener el diseño sugerido en el proyecto de Código Procesal Civil enviado por el Gobierno al Congreso Nacional.

$\mathrm{Si}$, en cambio, las ventajas de la unificación de jurisprudencia pretendida por el recurso extraordinario son relevantes y los problemas asociados a su aplicación son también relevantes, entonces se deben introducir las correcciones legislativas o realizar las adecuaciones institucionales que permitan superar estos problemas.

En tercer lugar, si ni las ventajas de la unificación de jurisprudencia pretendida por el recurso extraordinario ni los problemas asociados a su aplicación son relevantes, entonces será necesario evaluar si merece la pena sustituir el tradicional recurso de casación por este nuevo recurso en el proyecto de Código Procesal Civil.

Por último, si las ventajas de la unificación de jurisprudencia pretendida por el recurso extraordinario no son relevantes y los problemas asociados a su aplicación son relevantes, entonces dicho recurso debería ser derechamente desestimado.

3 Explicaciones dadas por el representante del Ministerio del Trabajo durante la tramitación del proyecto de ley que introdujo el recurso de unificación de jurisprudencia en el Código del Trabajo. En Segundo informe de la Comisión de Trabajo del Senado, p. 284. 
Conviene reconocer que el uso de la expresión "relevante" importa una valoración y que entre los extremos "relevante" y "no relevante" se encuentra una indeterminada gama de matices. Sin embargo, una tal limitación no conduce a desconocer la necesidad de identificar los objetivos y problemas mencionados. Y ello porque el cruce de las respuestas a estas dos preguntas no es más, ni menos, que un ejercicio de ponderación, es decir, la consideración del peso de los intereses en colisión. La ponderación, a su turno, es un ejercicio habitual en la adopción de decisiones en el campo de la argumentación práctica general. Y este es, precisamente, el ámbito en el que se mueve el Derecho, en general, y la adopción de decisiones legislativas, en particular.

\section{ESTRUCTURA DEL TRABAJO}

La exposición que sigue se vertebra en tres apartados. En el primero de ellos se explicitan los objetivos perseguidos con la unificación de jurisprudencia pretendida por el recurso extraordinario. En el siguiente se identifican los problemas asociados a la unificación de jurisprudencia pretendida por el recurso extraordinario. El último, en el que se presentan las conclusiones, se dedica a responder las preguntas de la investigación a partir de los elementos entregados en los dos apartados anteriores.

\section{1) Ventajas DEL RECURSO EXTRAORdinARIO}

Resulta perfectamente posible inferir las ventajas de la unificación de jurisprudencia pretendida por el recurso extraordinario a partir de su configuración legislativa. Entre tales ventajas parece conveniente destacar las siguientes: a) asegura la igualdad en la aplicación de la ley; b) incrementa la seguridad jurídica; c) disminuye la litigiosidad; d) facilita la tarea interpretativa de los tribunales; e) precisa los costos que tienen ciertas decisiones jurídicas; f) incrementa la confianza en el sistema judicial; g) fortalece la legitimidad del Poder Judicial; y h) disminuye la intervención de elementos extrajurídicos en las decisiones judiciales. Las ventajas expresadas en las letras c), d) y e) responden a una perspectiva de análisis económico del Derecho. Los tres últimos, por su parte, pueden ser genéricamente denominados objetivos políticos. A continuación serán revisados en este mismo orden. 


\section{(1.1) ASEgura LA IGUALDAD EN LA APLICACión DE LA LEY}

El recurso extraordinario pretende la unificación de la jurisprudencia, esto es, que los casos iguales sean tratados de la misma manera. Significa que mediante su aplicación se persigue asegurar la igualdad en la aplicación de la ley. Para comprender el modo en que dicho recurso se orienta al logro de este objetivo, conviene exponer algunas consideraciones.

El artículo 19, número 2, de la Constitución chilena dispone que asegura a todas las personas "la igualdad ante la ley" y que " $n i$ la ley ni autoridad alguna podrán establecer diferencias arbitrarias". El artículo 19, número 3, por su parte, establece que la Constitución asegura a todas las personas "la igual protección de la ley en el ejercicio de sus derechos". Explicitando esta exigencia, la doctrina ha formulado una distinción entre igualdad en la ley e igualdad en la aplicación de la ley. La primera constituye un mandato al legislador, mientras la segunda constituye un mandato a quien ejerce jurisdicción ${ }^{4}$.

La igualdad en la aplicación de la ley consiste en que esta debe ser aplicada de la misma manera a lo igual y debe ser aplicada de diversa manera a lo desigual. Como se puede advertir, este concepto se construye sobre la base de tres elementos: un objeto a aplicar, un modo en que debe ser aplicado y una condición para que se aplique de este modo. El objeto a aplicar es la ley. El modo en que la ley debe ser aplicada es "de la misma manera" o "de diversa manera". La condición para que la ley se aplique de la misma manera es que se trate de "lo igual" y para que se aplique de diversa manera es que se trate de "lo desigual".

En consecuencia, cada vez que el juzgador se encuentre frente a dos casos iguales deberá tratarlos de la misma manera, es decir, aplicarles la ley de la misma manera. En el mismo sentido se han pronunciado autores

4 Explicando las expresiones igualdad en la ley e igualdad ante la ley (o en la aplicación de la ley), Figueroa García-Huidobro, Rodolfo (2008) "Igualdad y discriminación". Disponible en derechoshumanos.udp.cl/wp-content/uploads/2009/07/ihualdad-y-no-discrim. pdf, en línea, [fecha de visita 22 julio 2008], p. 34, afirma: "La igualdad en la ley es una exigencia que está referida a los contenidos de la ley, en el sentido de que ellos deben satisfacer un determinado estándar de igualdad. Si asi no ocurre, podrá considerarse que la ley es contraria al principio de igualdad y podrá reclamarse su inconstitucionalidad, cuando esté previsto. Por ello, el principio de igualdad en esta dimensión representa una cláusula que limita el proceder del órgano legislativo. En cambio, la igualdad ante la ley constituye una exigencia que apunta no a sus contenidos sino a su aplicación, sea por parte de la autoridad administrativa o de cualquier otro agente, en el sentido de que dicha aplicación debe ser igualitaria. Por ello, con frecuencia, se alude a esta dimensión también como igualdad en la aplicación de la ley. Si la aplicación de preceptos legales no es igualitaria, se podrá reclamar contra el acto especifico de aplicación de la ley, no contra la ley". 
como De Asís ${ }^{5}$, Peces-Barba ${ }^{6}$, García Toma ${ }^{7}$, Parra $^{8}$, Castillo Alva ${ }^{9}$, Hei$\mathrm{se}^{10}$, y Hernández ${ }^{11}$, entre otros. Y este es, precisamente, uno de los objetivos que se persiguen con el recurso extraordinario.

5 Textualmente expresa el profesor De Asís Roig, Rafael (1995). Jueces y normas. La decisión judicial desde el ordenamiento. Madrid: Marcial Pons, 1995, p. 248: "En relación con el Poder Judicial, y concretamente con su actuación, este sentido de la igualdad [como no discriminación] impide establecer diferencias de trato entre los ciudadanos; impone resolver de forma idéntica casos idénticos". Y confirma su posición en De Asís Roig, Rafael (1999). "Breves reflexiones sobre los valores y los derechos en la Constitución Española en su veinte aniversario". Revista de Derecho Constitucional, El Salvador, 1999, $\mathrm{N}^{\circ} 33$, vol. T. 1. Disponible en: http://www.csj.gob.sv/Doctrina.nsf 15a638ba98cb9b7ea86256d47004bac46/b90b821702451afe0625694d00527df4?OpenDocu ment [fecha de visita 11 noviembre 2008], donde afirma: "Quiero anunciar ya de antemano que defiendo la necesidad de existencia de una obligación de resolver casos idénticos en idénticos sentido", exigencia que se deduce con meridiana claridad "del principio de igualdad, tanto en su dimensión formal, a partir de la cual se exigiría el trato idéntico de situaciones idénticas, cuanto en su dimensión material, a partir de la cual se facilitaría un trato diferente en virtud de criterios no arbitrarios".

$6 \quad$ Al respecto afirma Peces-Barba Martínez, Gregorio (1999). Curso de derechos fundamentales. Madrid: Universidad Carlos III de Madrid y Boletín Oficial del Estado, p. 285: " $\mathrm{La}$ igualdad de trato formal con carácter general supone ...que un mismo órgano no puede modificar arbitrariamente el sentido de sus decisiones en casos sustancialmente iguales".

7 Sobre el punto sostiene García Toma, Víctor (2009). "Las sentencias: conceptualización y desarrollo jurisprudencial en el Tribunal Constitucional peruano". En Ferrer Mac-Gregor, Eduardo y Zaldívar Lelo de Larrea, Arturo (coordinadores): La Ciencia del Derecho procesal constitucional. Estudios en homenaje a Héctor Fix-Zamudio en sus cincuenta años como investigador del Derecho, T. V. juez y sentencia constitucional. Disponible en: http://www.incipp. org.pe/modulos/documentos/descargar.php?id=231 [fecha de visita 9 febrero 2009], p. 400: "A manera de colofón es dable consignar que el precedente tiene como objetivos jurídicos el propender a la (...) igualdad, en la interpretación y aplicación del derecho”.

8 En palabras de Parra, María Victoria (2004). "El precedente judicial en el Derecho comparado". Criterio Jurídico, No 4. Disponible en: http://criteriojuridico.puj.edu.co/.../10_239_ mvparra_precedente_judicial.pdf [fecha de visita 13 febrero 2009], p. 249, se "justifica el uso de los precedentes en la vigencia del principio de igualdad, entendido como la prerrogativa a recibir trato igual por parte de las instancias judiciales; en tanto se entiende que casos iguales o similares deben recibir igual tratamiento".

9 Castillo Alva, José Luis (2009). "El uso de los precedentes judiciales como técnica de argumentación racional. Su alcance y valor en el Derecho peruano". Disponible en: http:// www.unifr.ch/ddp1/derechopenal/articulos/a_20080521_46.pdf [fecha de visita 6 febrero 2009], p. 5, sostiene que la ventaja del uso del precedente se encuentra, entre otros motivos, en la "realización del principio de igualdad".

10 Moreno Ortiz, Luis Javier (2009). “¿Hacia un sistema jurídico sin precedentes?”. Disponible en: http://www.usergioarboleda.edu.co/derecho/haciaunsistemajuridicodepresedentes.html [fecha de visita10 mayo 2009] expresa al respecto: "La consagración constitucional de la igualdad implica que los jueces deberán juzgar los casos semejantes como semejantes y los diferentes como diferentes, enunciado que sintetiza muy adecuadamente el sentido de un 'sistema de precedentes".

11 Hernández Martínez, María del Pilar (1994). "El principio de igualdad en la jurisprudencia del Tribunal Constitucional español (Como valor y como principio en la aplicación jurisdiccional de la ley)". Boletín Mexicano de Derecho Comparado, Año XXVII, No 81, sep.-dic. Disponible en: http://www.juridicas.unam.mx/publica/rev/boletin/cont/81/art/art4.htm [fecha de visita 10 mayo 2009], p. 701: "Al hilo discursivo podríamos decir que si la igualdad ante la ley implica una exigencia de que todos los individuos se encuentran sometidos a las mismas normas y a los mismos tribunales, luego entonces, cuando los individuos o los supuestos de hecho que se presentan -bien ante el legislador, administración pública y jueces y tribunales-, son iguales, deben ser tratados del mismo modo, y en caso de que sean distintos deben recibir trato diferente". 
Ahora bien, aplicar la ley de la misma manera a los casos iguales significa dos cosas. En primer lugar, que frente a casos iguales, es decir, casos que presentan los mismos hechos relevantes, se deben aplicar las mismas disposiciones. En segundo lugar, y como precisión de lo anterior, que esas mismas disposiciones deben ser interpretadas de la misma manera. El incumplimiento de cualquiera de estas dos exigencias implica contravenir la igualdad en la aplicación de la ley. Ello se debe a que aplicar dos disposiciones distintas o dos interpretaciones distintas a casos iguales conducirá a un tratamiento diverso de esos casos iguales.

\section{(1.2) INCREMENTA LA SEGURIDAD JURÍDICA}

Mediante la unificación de jurisprudencia, es decir, mediante el trato igual de casos iguales, el recurso extraordinario genera un beneficio tan relevante como asegurar la igualdad en la aplicación de la ley: incrementar la seguridad jurídica.

El profesor Peces-Barba explica que la seguridad es un valor que "supone la creación de un ámbito de certeza, de saber a qué atenerse, que pretende eliminar el miedo y favorecer un clima de confianza en las relaciones sociales, entre los seres humanos que intervienen y hacen posibles esas relaciones”. De este modo, precisa, es algo intensamente vinculado a la vida de la persona, a su dignidad y al disfrute de relaciones intersubjetivas sin incertidumbres ${ }^{12}$.

Ahora bien, la seguridad jurídica tiene evidente impacto en la actividad judicial. En palabras de Moreno, "las decisiones judiciales deben ser, con un grado razonable de certidumbre, "predecibles", a fin de que la conducta que el derecho regula pueda ser "proyectable", de que las personas puedan saber con un margen suficiente de razonabilidad a qué atenerse"13. Esta exigencia de seguridad significa, como explica Magro desde una perspectiva penal, que "todo ciudadano tiene asi el derecho a saber, con nitida precisión, si un hecho es o no lícito, incluso si es o no delito; si un tipo especifico se integra con tres o con cinco requisitos" 14 .

$\mathrm{Si}$ los tribunales deciden casos iguales de diversa manera entonces las decisiones judiciales son impredecibles y el ciudadano no sabe a qué atenerse. Por el contrario, si se resuelven casos iguales de la misma mane-

12 Expresa Peces-Barba (1999) p. 246, que la seguridad "permite el desarrollo de la dignidad humana y hace posible la vida, el mantenimiento de esa vida con garantias y la posibilidad de una comunicación con los demás, sin sobresaltos, sin temor y sin incertidumbre".

13 Moreno (2009).

14 Magro Servet, Vicente (2008). "Hacia un régimen de consultas de las Audiencias Provinciales y Tribunales Superiores de Justicia al Tribunal Supremo para unificación de doctrina". Diario La Ley, No 7047, Sección Doctrina, Año XXIX, Editorial La Ley, p. 12. 
ra, entonces se incrementa la seguridad jurídica. Esto significa, desde el ángulo que interesa a este trabajo, que resolver casos iguales de la misma manera incrementa la seguridad jurídica.

\section{(1.3) Ventajas asociadas al aNÁlisis eCONómiCo Del DeRECHO}

Desde el análisis económico del Derecho también se pueden identificar algunas ventajas derivadas de la unificación de jurisprudencia pretendida por el recurso extraordinario.

La primera de ellas se refiere a que disminuye la litigiosidad ${ }^{15}$. Si los operadores jurídicos cuentan con interpretaciones uniformes, se encontrarán en mejores condiciones para tomar decisiones respecto de la conveniencia de litigar. En efecto, si las decisiones judiciales son impredecibles, ambas partes contarán con una alta expectativa respecto de la posibilidad de triunfar en un litigio ${ }^{16}$. De este modo, la unificación de jurisprudencia incrementa las posibilidades de acuerdos entre las partes en el proceso ${ }^{17}$.

Otra ventaja del recurso extraordinario es que facilita la tarea interpretativa de los órganos jurisdiccionales. En efecto, si el significado de las disposiciones ha sido precisado por las sentencias dictadas por la Corte Suprema en unificación de jurisprudencia, el juzgador del caso actual no necesita repetir esa misma tarea. Resulta posible sostener que esa simplificación de la actividad interpretativa se justifica en el ahorro de recursos. Y la lógica económica indica que entre las diversas opciones que conducen a

15 En este sentido, Magro Servet, Vicente (2007). "La unificación de criterios: una anhelada aspiración”. Diario La Ley, No 6498, Sección Doctrina, año XXVII, Editorial La Ley, p. 4, afirma que "por medio de una adecuada unificación de criterios, podrian quedar resueltos extrajudicialmente muchos conflictos si las partes conocieran de antemano el criterio del tribunal en una materia concreta".

16 En un interesante estudio desde el análisis económico del Derecho, García, José Francisco (2007). "Reforma al Poder Judicial: una agenda para la discusión". Serie Informe Político, Libertad y Desarrollo, No 100. Disponible en: http://www.ild.cl/biblioteca/serie/politico/88_serie_informe_politico.pdf [fecha de visita 14 febrero 2009], p. 38, explica que "si los agentes involucrados no pueden anticipar razonablemente cuál será el criterio de decisión de los tribunales, dicha incertidumbre se traducirá en múltiples costos que dificultarán las relaciones entre los actores sociales. En efecto, si una misma norma tiene distintas interpretaciones y alcances, cuando se repitan situaciones similares en el futuro, el incentivo para que terminen en juicio es elevado, ya que ambas partes tendrán la expectativa de que el tribunal los favorezca". Y añade: "En ese caso, todo el costo que significó el primer juicio no constituye ningún aporte a los otros casos acaecidos posteriormente, obligando al pais y a las personas a incurrir una y otra vez en costos judiciales para casos que son prácticamente idénticos, con el consecuente aumento de la conflictividad, incertidumbre e inseguridad".

17 En este sentido, afirma García (2007) p. 38: "Desde la perspectiva económica, el conocimiento de cómo los tribunales aplicarán el derecho tiene un importante efecto en el nivel de litigiosidad. Para este razonamiento debemos asumir como evidente que los arreglos son más convenientes y baratos que los litigios". 
un mismo resultado debe preferirse la de menor costo, a menos que existan razones en sentido contrario ${ }^{18}$.

En tercer lugar, y siempre desde el análisis económico del Derecho, con el recurso extraordinario se incrementan las posibilidades de prever los costos que en materia de litigación pueden generar ciertas decisiones. En efecto, "en un sistema en donde no existe precedente [unificación de jurisprudencia, se diría aquí], la contingencia es muy alta. $Y$ si no existe seguridad acerca de cómo se debe interpretar el derecho y cómo se comportarán nuestros tribunales, entonces los ciudadanos, ante la incertidumbre, deberán tomar precauciones adicionales y eventualmente cubrir variadas alternativas en relación con el cumplimiento de las normas vigentes, incurriendo en mayores costos de lo que hubieran sido necesarios si existiera un actuar uniforme y obligatorio por parte de los tribunales de justicia"19.

\section{(1.4) OBJETIVOS DE CARÁCTER POLÍTICO}

El recurso extraordinario presenta ventajas o beneficios que de manera genérica pueden ser calificados como políticos.

El primero de ellos se relaciona con el incremento de la confianza en el funcionamiento del sistema jurisdiccional por parte de la ciudadanía y de los operadores jurídicos ${ }^{20}$. En efecto, si los tribunales dictan iguales decisiones frente a casos que presentan iguales hechos, las personas sabrán a qué atenerse ${ }^{21}$. Esta reiteración de decisiones se produce si se respetan

18 Las ventajas económicas del precedente son destacadas por Figueroa (2008) p. 36, en los siguientes términos: "La seguridad jurídica reduce la contingencia. Dicho al revés, donde no existe un sistema de precedente la contingencia es muy alta, lo que hace que el sistema sea deseconómico, y con esto entramos en una tercera función. En efecto, si no existe seguridad acerca de cómo se interpretará el derecho y cómo se comportarán los tribunales, entonces los ciudadanos, ante la incertidumbre, deberán tomar precauciones adicionales y eventualmente cubrir varias alternativas en relación con el cumplimiento de las normas vigentes, probablemente incurriendo en mayores costos que los que hubieran sido necesarios, de existir un modo de proceder uniforme y obligatorio de parte de los órganos judiciales, conocido por todos. Además, resulta deseconómico un sistema que obliga a considerar cada caso como si fuera un caso nuevo. En los sistemas donde no se reconoce el precedente, cada caso puede ser resuelto de cualquier manera; toda alternativa de solución que se presente será una alternativa disponible, de modo que cada caso puede estimarse como un caso nuevo. Pues bien, estimar cada caso como un caso nuevo es deseconómico".

19 Heise Burgos, Gustavo (2009). "Reflexiones en torno a la Jurisprudencia y el precedente judicial en la cultura jurídica chilena”. Disponible en: http:// www.jornadasderechopublico. ucv.cl/.../Reflexiones\%20en\%20torno\%20a\%20la\%20Jurisprudencia\%20y... [fecha de visita 10 mayo 2009], pp. 4-5.

20 Magro (2008) p.11, afirma al respecto: "La inseguridad jurídica provoca una merma en la credibilidad de la justicia, y los factores que coadyuven en conseguir una unidad de criterio servirán para que los ciudadanos y los profesionales que a estos representan y defienden eleven su nivel de confianza en la justicia".

21 Remón Peñalver, Jesús (2007). "La lucha por la seguridad jurídica”. Disponible en: http:// www.clubarbitraje.com/files/docs/libro_fusion.pdf [fecha de visita 23 febrero 2009], explica que el dogma de imperio de la ley y racionalidad del legislador "está siendo paulatinamente 
las interpretaciones contenidas en las decisiones de unificación de jurisprudencia pronunciadas por la Corte Suprema al conocer del recurso extraordinario.

Un segundo beneficio de carácter político que se puede atribuir al recurso extraordinario es el incremento de la legitimidad del sistema judicial. En efecto, la sumisión de los demás tribunales del Poder Judicial a las interpretaciones formuladas por la Corte Suprema en unificación de jurisprudencia constituiría una práctica que permitiría incrementar la legitimidad de este sistema. Ello se debe a que la "obligación de resolver un caso como ha sido resuelto en otro, precedente, implica suponer que la decisión del caso anterior es la correcta, ya que si el tribunal considera que no es la correcta debe probar y justificar el cambio del precedente y el modo de resolver" 22 .

Por último, con el recurso extraordinario se disminuye la injerencia de motivaciones extrajurídicas para resolver un caso. En este sentido se debe reconocer que los jueces pueden resultar influidos por sus creencias respecto de las políticas públicas más convenientes, por sus necesidades humanas básicas de ser estimado o la de tener $\operatorname{poder}^{23}$, o por sentimientos de simpatía, odio o temor ${ }^{24}$. Esas motivaciones pueden ser restringidas exclusivamente a la Corte Suprema si la posibilidad de apartarse de la jurisprudencia uniforme se limita a esta última, como expresamente lo contempla el Código Procesal Civil ${ }^{25}$. Es efectivo que en este caso no se suprimirían aquellas circunstancias extrajurídicas. Sin embargo, y por contrapartida, su injerencia se limitaría al máximo órgano jurisdiccional, en lugar de permitir que incidan en cada juez y tribunal.

sustituida por una lógica de red (XIOL RÍOS) articulada en torno a una trama de estructuras sectoriales autónomas dotadas de sus particulares regimenes jurídicos (Derecho global sin Estado) $y$ de sus propios centros y pautas de decisión". Pero para que un sistema asentado sobre estas bases funcione correctamente es necesario "que asuma el principio de vinculación al precedente para que puedan conocerse las lineas de razón que sirven de fundamento a sus decisiones y todo el mundo pueda saber a qué atenerse".

22 Heise (2009) p. 5.

23 En este sentido, afirma Linares, Sebastián (2004). "Política y gobierno". Vol. XI, No 1, primer semestre. Disponible en: http://www.politicaygobierno.cide.edu/.../Sebastian_ Linares_p-73-126.pdf [fecha de visita 10 mayo 2009] p. 94, que "el contenido axiológico o político concreto de las instituciones -o de los valores que el juez persigue- suele encubrirse mediante un discurso racionalista que atribuye una supuesta neutralidad axiológico-jurídica a las leyes o instituciones formales, manifestada por su carácter abstracto y general, su publicidad, y el hecho de que incluso los gobernantes se encuentran sujetos a las mismas".

$24 \quad \mathrm{Al}$ respecto expresa Moreno (2009): "El juez no puede sucumbir en la tentación de juzgar a partir de sus simpatías o sus odios, o de sus deseos de beneficiar a las partes movido por el miedo (amenaza) o el ánimo de 'provecho' personal (soborno, coima, etc.), o de su debilidad ante las presiones de su entorno (familia, superiores, grupo social, opinión pública)". Artículo 354, letra d), del Código Procesal Civil. 


\section{2) Problemas del Recurso eXtraordinario}

Los problemas asociados a la unificación de jurisprudencia pretendida por el recurso extraordinario derivan precisamente de su disonancia con el modo en que se entiende el Derecho en el marco de la familia europeo continental. El primero de ellos se refiere a la concepción prevaleciente respecto del efecto relativo de las sentencias. El segundo consiste en la inexistencia de una cultura judicial tendiente a respetar las interpretaciones de la Corte Suprema. El tercero es el rechazo que presenta parte importante de la doctrina a la idea de unificar la jurisprudencia. Por último, el recurso extraordinario pone en evidencia un problema político y jurídico relativo a la función de la Corte Suprema.

\section{(2.1) LA CONCEPCIÓN PREVALECIENTE SOBRE EL EFECTO RELATIVO DE LAS SENTENCIAS}

Un primer problema con el que se encuentra el cumplimiento de los objetivos del recurso extraordinario es el modo en que se ha entendido tradicionalmente el artículo $3^{\circ}$, inciso segundo, del Código Civil. En él se dispone: "Las sentencias judiciales no tienen fuerza obligatoria, sino respecto de las causas en que actualmente se pronunciaren". Esta disposición ha sido interpretada en el sentido que las sentencias solo obligan a los litigantes el respectivo proceso y, en consecuencia, no pueden afectar a terceros, por regla general ${ }^{26}$. Es lo que se denomina el efecto relativo de las sentencias judiciales.

Esta idea ha sido sostenida por la doctrina chilena al menos desde Luis Claro Solar, quien al respecto expresaba que "la sentencia dictada en una causa no puede ser invocada de un modo general para resolver todos los juicios en que se discuta la misma cuestión de derecho o en que el juez tenga que aplicar la misma disposición legal" 27 . Igual perspectiva se presenta en las reconocidas obras de Alessandri, Somarriva y Vodanovic ${ }^{28}$, de

26 Es necesario advertir que, en todo caso, esta interpretación no es uniforme en la doctrina chilena. Algunos autores, como DucCi Claro, asocian el artículo $3^{\circ}$, inciso segundo, del Código Civil a la cosa juzgada. Esto significa que el alcance relativo de la sentencia se refiere exclusivamente a lo decidido en ella, es decir, a la parte resolutiva. Al respecto ver, por ejemplo, a Ducci Claro, Carlos (2002). Derecho civil. Parte general. Santiago: Editorial Jurídica de Chile, p. 108.

27 La cursiva ha sido añadida para destacar la contradicción entre lo expresado entre Luis Claro Solar y lo pretendido por el recurso extraordinario. El autor inmediatamente precisa lo siguiente: "Al tratar de la interpretación de las leyes veremos que esta fuerza de una sentencia es puramente moral, de doctrina, y solo vale en lo que puede pesar la opinión más o menos ilustrada de los magistrados que subscriben ese fallo". Ver Claro Solar, Luis (1992). Explicaciones de Derecho civil chileno y comparado. Santiago: Editorial Jurídica de Chile, p. 34.

28 Alessandri Rodríguez, Arturo et al. (2005). Tratado de Derecho Civil. Santiago: Editorial Jurídica de Chile, p. 132. 
Hernán Larraín Ríos ${ }^{29}$, de Gonzalo Figueroa Yáñez ${ }^{30}$ y de Juan Colombo Campbell ${ }^{31}$, entre otras.

Especificando esta idea, algunos autores han explicitado que la sentencia de un tribunal no lo obliga a fallar de la misma manera en análogos casos futuros. Del mismo modo, la sentencia de un tribunal jerárquicamente superior en ningún caso puede resultar vinculante para uno inferior. En este sentido se puede citar a Carlos Ducci Claro ${ }^{32}$ y a los ya mencionados Figueroa Yáńez ${ }^{33}$ y Alessandri, Somarriva y Vodánovic ${ }^{34}$.

Lo expuesto muestra que existe un elevado consenso en la doctrina chilena más tradicional respecto del modo en que se debe entender el artículo $3^{\circ}$, inciso segundo, del Código Civil. En él se consagraría la relatividad de las sentencias, incluida por cierto las de la Corte Suprema, en el sentido que aquellas no pueden producir efecto más allá de los intervinientes en el respectivo juicio, con las excepciones señaladas. Esta concepción implica una determinada forma de entender el alcance de las decisiones judiciales y, por lo mismo, una determinada forma de comportarse frente a las mismas por parte de los operadores jurídicos.

Como se puede apreciar, esta concepción sobre el efecto relativo de las sentencias constituye un primer problema para el cumplimiento de los objetivos del recurso extraordinario. En efecto, con este recurso se pretende que las sentencias de la Corte Suprema, en particular las interpretaciones contenidas en aquellas, sean seguidas por el resto de los tribunales que integran el Poder Judicial. Dicho de otro modo, se pretende que las decisiones interpretativas de la Corte Suprema tengan efectos más allá de las

29 Comparando a la ley con la sentencia, Larraín expresa que "la sentencia judicial, en cambio, solo obliga a las partes que han litigado en el juicio en que la sentencia se dicta". LARRAín Ríos, Hernán (2004) Lecciones de Derecho Civil. Santiago: Editorial Jurídica de Chile, p. 35.

$30 \mathrm{Al}$ referirse a la interpretación judicial de la ley, Figueroa sostiene que la fuerza obligatoria de dicha interpretación "es muy limitada. Salvo contadas excepciones, solo alcanza a los litigantes”. Figueroa Yáñez, Gonzalo (1992). Curso de Derecho Civil. Santiago: Editorial Jurídica de Chile, p. 126.

$31 \mathrm{Al}$ respecto, Соцомво incluye un epígrafe del siguiente tenor: "Los efectos finales del proceso se producen en el conflicto que se resolvió a través de él'. Y precisa en el texto bajo dicho epígrafe: "Terminado el proceso, los efectos de la sentencia salen de él para volver a la realidad como única forma de poner término al conflicto que lo motivó". CоLомво CAMpBell, Juan (1997). Los actos procesales. Santiago: Editorial Jurídica de Chile, p. 145.

32 Al explicar el sentido y significado del artículo $3^{\circ}$, inciso segundo, del Código Civil, DucCI sostiene que "un tribunal no está jamás ligado por las decisiones que haya podido adoptar precedentemente; puede siempre cambiar de opinión. Igualmente, ningún tribunal está obligado a respetar la jurisprudencia de un tribunal superior". Ducci (2002) p. 105.

33 La interpretación sostenida en la sentencia, afirma FigueroA, "Ni siquiera ata al juez que falla el conflicto; puede aquel, en casos análogos, resolver en forma diversa”. Figueroa (1992) p. 126.

34 Al respecto, estos autores han afirmado que, salvo contadas excepciones, la interpretación judicial de una determinada disposición "solo alcanza a los litigantes. Ni siquiera ata al juez que falla el conflicto; puede aquel en casos análogos resolver en forma diversa". ALESSANDRI (2005) p. 184. 
partes de la causa en que se han pronunciado. Y, según se ha mostrado, esto se contrapone a la forma en que se entienden las decisiones judiciales y al modo en que los operadores jurídicos históricamente se han comportado frente a ellas a la luz del artículo $3^{\circ}$ del Código Civil.

\section{(2.2) FAlTA DE UNA CULTURA JUdiCIAL TENDIENTE A RESPETAR LAS INTERPRETACIONES DE LA CORTE SUPREMA}

Un segundo problema con el que se enfrentará la aplicación del recurso extraordinario es la falta de una cultura judicial tendiente a respetar las interpretaciones de la Corte Suprema cuando adopta una decisión en unificación de jurisprudencia. En este sentido es posible citar lo acaecido con el recurso de unificación de jurisprudencia laboral. Esto se debe a que ambos recursos presentan coincidencia en sus fines y en sus causales de procedencia.

En efecto, y en cuanto a la finalidad, el recurso extraordinario pretende, como indica el epígrafe del artículo 354 del proyecto de Código Procesal Civil, unificar la jurisprudencia. Al respecto, el mismo precepto expresa: "La función de la Corte Suprema es preservar la coherencia y unidad de los criterios de decisión en los tribunales del pais en virtud del recurso extraordinario. En consecuencia, ejercerá su función de unificación" en los casos que la misma disposición precisa. La coincidente finalidad del recurso de unificación de jurisprudencia laboral, por su parte, se expresa en su propia denominación (art. 483 del Código del Trabajo).

En cuanto a las causales de procedencia, una de las contempladas para el recurso extraordinario coincide con la causal establecida para el de unificación de jurisprudencia laboral. Al respecto el artículo 354, número 2, del proyecto de Código Procesal Civil dispone que la Corte Suprema ejercerá su función de unificación cuando la jurisprudencia previa fuere contradictoria entre sí. El Código del Trabajo, por su parte, dispone en el artículo 483 que la unificación de jurisprudencia procederá cuando respecto de la materia de Derecho objeto del juicio existieren distintas interpretaciones sostenidas en uno o más fallos firmes emanados de Tribunales Superiores de Justicia.

Esta doble coincidencia permite afirmar que lo acaecido con el recurso de unificación de jurisprudencia laboral puede, en alguna medida no desdeñable, anticipar lo que acaecerá con el recurso extraordinario.

Pues bien, la evidencia muestra que el recurso de unificación de jurisprudencia laboral no ha cumplido sus objetivos respecto del resto del Poder Judicial. La Corte Suprema ha tendido a uniformar su jurisprudencia en diversas materias del ámbito laboral. Pese a ello, en muchos casos las Cortes de Apelaciones no han prestado atención a las interpretaciones sostenidas en las sentencias de unificación. A continuación se evidencian estas dos aseveraciones. 
$\mathrm{Al}$ enfrentar diversos casos que coinciden en todas sus propiedades relevantes, la Corte Suprema ha tendido, en general, a mantener la interpretación de las materias de Derecho que han sido objeto del juicio. Dicho de otro modo, al conocer del recurso de unificación de jurisprudencia, normalmente ha decidido de la misma manera casos iguales.

Así, por ejemplo, reiteradamente ha establecido que las indemnizaciones por años de servicios contemplada en el estatuto docente, Ley 19.070, y la indemnización por renuncia voluntaria establecida a favor de los profesores por el artículo $2^{\circ}$ transitorio de la Ley 20.158 son incompatibles $^{35}$. Del mismo modo, uniformemente ha sostenido que el plazo de prescripción de las acciones laborales es de dos años mientras el contrato está vigente y de seis meses una vez concluido el mismo ${ }^{36}$. Por otra parte, ha sentenciado de modo uniforme que los trabajadores con remuneración mixta, es decir, sueldo fijo mensual más asignaciones variables, solo tienen derecho a la semana corrida si la parte variable de la remuneración se

35 En cuanto a la incompatibilidad de bonificación e indemnización, ver sentencias de unificación de jurisprudencia pronunciadas por la Corte Suprema. 4 de agosto de 2010. Rol No 2578-2010. Disponible en http://www.pjud.cl/modulos/BusqCausas/BCA_esta402.php?r owdetalle=AAANoPAAkAABTvEAAA\&consulta $=100 \&$ causa $=2578 / 2010 \&$ numcua $=276$ 95\&secre=UNICA. [fecha de visita 8 de abril de 2011]; Corte Suprema. 3 de noviembre de 2010. Rol No 5010-2010. Disponible en http://www.pjud.cl/modulos/TribunalesPais/ TRI_esta402.php? rowdetalle $=$ AAANoPAAyAAB 1 viAAC\&consulta $=100 \&$ glosa $=\&$ causa $=$ 5010/2010\&numcua $=41603 \&$ secre=UNICA. [fecha de visita 16 diciembre 2010]; Corte Suprema. 9 de noviembre de 2010. Rol No 5833-2010. Disponible en http://www.pjud.cl/ modulos/TribunalesPais/TRI_esta402.php?rowdetalle=AAANoPAAyAAB1MvAAE\&consult $a=100 \&$ glosa $=\&$ causa $=5833 / 2010 \&$ numcua $=42538 \&$ secre $=$ UNICA. [fecha de visita 17 diciembre 2010]; Corte Suprema. 11 de noviembre de 2010. Rol No 5011-2010. Disponible en http://www.pjud.cl/modulos/TribunalesPais/TRI_esta402.php?rowdetalle=AAANoPAA yAAB 1 xkAAC\&consulta $=100 \&$ glosa $=\&$ causa $=5011 / 2010 \&$ numcua $=43000 \&$ secre $=$ UNI CA. [fecha de visita 20 diciembre 2010]; Corte Suprema. 15 de noviembre de 2010. Rol No 4911-2010. Disponible en http://www.pjud.cl/modulos/TribunalesPais/TRI_esta402.php?r owdetalle $=$ AAANoPAAyAAB2ImAAA\&consulta $=100 \&$ glosa $=\&$ causa $=4911 / 2010 \&$ numcua $=43425 \&$ secre=UNICA. [fecha de visita 20 diciembre 2010]; Corte Suprema. 29 de marzo de 2011. Rol 7828-2010. Disponible en http://www.poderjudicial.cl/modulos/BusqCausas/ BCA_esta402.php? rowdetalle=AAANoPAAyAAB2WLAAD\&consulta $=100 \&$ causa $=7828 / 2$ 010\&numcua $=11985 \&$ secre $=$ UNICA. [fecha de visita 17 diciembre 2010].

36 Con relación a los plazos de prescripción, ver sentencias de unificación de jurisprudencia pronunciadas por la Corte Suprema. 12 de octubre de 2010. Rol № 4510-2010. Disponivle en http://www.pjud.cl/modulos/BusqCausas/BCA_esta402.php?rowdetalle=AAANoPAAk AABUZSAAE\&consulta $=100 \&$ causa $=4510 / 2010 \&$ numcua $=38233 \&$ secre $=$ UNICA. $\quad[$ fecha de visita 9 de abril de 2011]; CS. Rol No 5010-2010; Corte Suprema. 23 de noviembre de 2010. Rol No 6455-2010. Disponible en http://www.pjud.cl/modulos/TribunalesPais/ TRI_esta402.php? rowdetalle=AAANoPAAyAAB 1\%2B\%2BAAJ \&consulta $=100 \&$ glosa $=\&$ causa $=6455 / 2010 \&$ numcua $=44795 \&$ secre $=$ UNICA. [fecha de visita 22 diciembre 2010]; Corte Suprema. 24 de marzo de 2011. Rol No 7104-2010. Disponible en http://www.pjud. $\mathrm{cl} /$ modulos/BusqCausas/BCA_esta402.php?rowdetalle=AAANoPAAyAAB2HQAAD\&cons ulta $=100 \&$ causa $=7104 / 2010 \&$ numcua $=11347 \&$ secre $=$ UNICA. [fecha de visita 28 noviembre 2011]. 
devenga diariamente ${ }^{37}$. En fin, sus sentencias coinciden en que la sanción por no pago de las cotizaciones previsionales establecida en el artículo 162 del Código del Trabajo solo es aplicable respecto del empleador que ha retenido, pero no ha enterado las cotizaciones previsionales del trabajador $^{38}$. Por último, y sin ánimo de ser exhaustivos, la Corte Suprema ha sentenciado en forma reiterada que las asignaciones de colación y movilización no deben incluirse en la última remuneración mensual, para efectos de calcular las indemnizaciones por años de servicio y sustitutiva del aviso $^{39}$.

Pese a esta tendencia unificadora, las Cortes de Apelaciones no parecen sentirse vinculadas por las decisiones adoptadas por la Corte Suprema. Así, por ejemplo, mediante sentencia de unificación de jurisprudencia, dictada el 4 de agosto de 2010, la Corte Suprema resolvió la incompatibilidad de la indemnización por años de servicio y el bono por retiro voluntario establecido en la Ley 20.158, respecto de los profesionales de la educación regidos por el estatuto docente ${ }^{40}$. Sin embargo, a fines del mismo mes, el 28 de abril, la Corte de Apelaciones de Talca se pronunció en sentido exactamente inverso ${ }^{41}$.

Por otro lado, en sentencia de unificación de jurisprudencia de 30 de abril de 2010, la Corte Suprema sostuvo que las asignaciones de colación y movilización no deben incluirse en el concepto última remuneración mensual que sirve como base de cálculo para determinar las indemnizaciones por ańos de servicios y sustitutiva del aviso ${ }^{42}$. Contrariando esta decisión, la Corte de Apelaciones de Concepción, mediante resolución de 18 de junio del mismo ańo, incluyó tales asignaciones en la referida base

37 En cuanto a la semana corrida, ver sentencia de unificación de jurisprudencia pronunciada por la Corte Suprema. 28 de marzo de 2011. Rol No 6115-2010. Disponible en http:// www.pjud.cl/modulos/BusqCausas/BCA_esta402.php?rowdetalle=AAANoPAAyAAB1zUA $A B \&$ consulta $=100 \&$ causa $=6115 / 2010 \&$ numcua $=11819 \&$ secre $=$ UNICA. $[$ fecha de visita 5 abril 2011].

38 Respecto de la sanción por no pago de las cotizaciones previsionales, ver sentencia de unificación de jurisprudencia pronunciada por la Corte Suprema. 8 de abril de 2010. Rol No 9265-2009. Disponible en http://www.pjud.cl/modulos/BusqCausas/BCA_esta402.php?ro wdetalle $=$ AAANoPAAPAADzb0AAL\&consulta $=100 \&$ causa $=9265 / 2009 \&$ numcua $=10773 \&$ secre=UNICA. [fecha de visita 22 diciembre 2010].

39 Sobre la excusión de las asignaciones de colación y movilización, ver sentencias de unificación de jurisprudencia pronunciada por la Corte Suprema. 21 de abril de 2010. Rol No 9603-2009. Disponible en http://www.poderjudicial.cl/modulos/BusqCausas/BCA esta402.php? rowdetalle=AAANoPAAPAAD0V7AAF \&consulta $=100 \&$ causa $=9603 / 2009 \&$ n umcua $=12508 \&$ secre $=$ UNICA. [fecha de visita 28 diciembre 2010] .

40 CS. Rol No 2578-2010.

41 El fallo de la Corte de Apelaciones de Talca se encuentra expresamente referido en la sentencia de unificación de jurisprudencia dictada por la CS. Rol No 7828-2010, en la que se revoca dicho fallo.

42 CS. Rol No 9603-2009. 
de cálculo ${ }^{43}$. Y lo mismo hizo la Corte de Apelaciones de Santiago mediante resolución de 26 de agosto de 2010, por la que rechazó el recurso de nulidad deducido en contra de la sentencia del juzgado del trabajo que también había incluido aquellas asignaciones en el concepto última remuneración mensual ${ }^{44}$.

En fin, y siempre por vía ejemplar, con fecha 8 de abril de 2010, la Corte Suprema dictó sentencia en unificación de jurisprudencia, en la que declaró que la sanción a que se refiere el artículo 162 del Código del Trabajo por no pago de las cotizaciones previsionales solo se aplica a los empleadores que han retenido pero no han enterado tales cantidades en la AFP respectiva ${ }^{45}$. La misma decisión adoptó en la sentencia de 20 de abril de $2010^{46}$. Pese a ello, en sentencia de 23 de junio del mismo ańo, es decir, dos meses después de pronunciadas aquellas decisiones, la Corte de Apelaciones de Santiago se pronunció en sentido contrario ${ }^{47}$.

Se podría pensar que es la falta de raigambre de la institución la que determina una ausencia de costumbre judicial. Es decir, las Cortes de Apelaciones no están, todavía, interiorizadas en su desempeño cotidiano con la observancia de la doctrina unificada. Sin embargo, tenemos un ejemplo en derecho comparado en que con más de veinte años nos muestra el mismo fenómeno.

El recurso de casación para unificación de doctrina en el proceso laboral español constituye un antecedente, siquiera cultural, del recurso extraordinario de unificación de jurisprudencia del proyecto de Código Procesal Civil ${ }^{48}$. El medio de impugnación espańol lleva funcionando

43 Esta decisión de la Corte de Apelaciones de Concepción es mencionada en la sentencia de unificación de jurisprudencia pronunciada por la Corte Suprema. 30 de noviembre de 2010. Rol No 6074-2010, que la revoca. Disponible en http://www.poderjudicial.cl/modulos/ TribunalesPais/TRI_esta402.php?rowdetalle=AAANoPAAyAAB1SzAAC\&consulta=100\&gl osa $=\&$ causa $=6074 / 2010 \&$ numcua $=45784 \&$ secre $=$ UNICA. [fecha de consulta 28 diciembre 2010].

44 Este fallo de la Corte de Apelaciones de Santiago es el objeto del recurso de unificación de jurisprudencia resuelto por la Corte Suprema. 26 de enero de 2011. Rol No 7362-2010, que precisamente revoca aquel fallo. Disponible en http://www.poderjudicial.cl/modulos/ TribunalesPais/TRI_esta402.php?rowdetalle=AAANoPAAyAAB1 WLAAB\&consulta=100\&glos $\mathrm{a}=\&$ causa $=7362 / 2010 \&$ numcua $=4390 \&$ secre $=$ UNICA. [fecha de consluta 27 diciembre 2010].

45 CS. Rol No 9265-2009.

46 Sentencia de unificación de jurisprudencia pronunciada por la Corte Suprema. 20 de abril de 2010. Rol No 852-2010. Disponible en http://cortesuprema.cl/causas/esta402.php?rowd etalle $=$ AAANoPAAPAADzoDAAO \&consulta $=100 \&$ glosa $=\&$ causa $=852 / 2010 \&$ numcua $=12$ 339\&secre=UNICA. [fecha de visita 29 diciembre 2010].

47 Esta decisión de la Corte de Apelaciones de Santiago se encuentra consignada en la sentencia dictada en unificación de jurisprudencia por la Corte Suprema. 10 de noviembre de 2010. Rol 5451-2010, que la revoca. Disponible en http://www.pjud.cl/modulos/TribunalesPais/ TRI_esta402.php? rowdetalle=AAANoPAAyAAB09pAAD\&consulta $=100 \&$ glosa $=\&$ causa $=54$ 51/2010\&numcua $=42783 \&$ secre $=$ UNICA. [fecha de consulta: 27 diciembre 2010] .

48 Entre otros, Rodolfo Caballero Muñoz en el Oficio $\mathrm{N}^{\circ} 50$ del Colegio de Abogados recibido en la Corte Suprema el 11 de noviembre de 2008. 
desde 1991 y también demuestra que los tribunales de justicia no obedecen las unificaciones reiteradas del Tribunal Supremo español. En este caso, como en el nuestro, no existe un precepto que asegure la decisión del máximo intérprete jurisdiccional como vinculante y, por lo tanto, los órganos que componen el Poder Judicial actúan bajo el principio de independencia decidiendo cada caso conforme a su propio juicio ${ }^{49}$.

Así, por ejemplo, podemos citar la sentencia de la Sala Cuarta del Tribunal Supremo español de 9 de julio de 2004 en que señala: "con reiteración viene declarando esta Sala (sentencia de 27 de octubre de 1997 y autos de 3 de marzo de 1998, 16 de diciembre de 2003, 16 de enero de 2004 y 26 de mayo de 2002), que la exigencia de que se trate de situaciones sustancialmente iguales restringe extraordinariamente la viabilidad del recurso de casación para la unificación de doctrina, cuando se trate de cuestiones que afectan a la calificación de lesiones a efectos del reconocimiento de los distintos grados de invalidez permanente porque, como se dijo en la sentencia de 19 de diciembre de 1991(...)". El Alto Tribunal español, como hemos comprobado también para nuestra Corte Suprema, debe repetir sus posiciones doctrinales, ya que los demás órganos jurisdiccionales no abandonan su sentido de independencia y, por lo tanto, no consideran imperativas las decisiones del máximo superior jerárquico. En este caso en particular, observamos que el tribunal español se está remontando a una de las primeras decisiones tomada en el ańo 1991, de modo que si no ha conseguido convencer de su argumento en 20 ańos, es probable que no lo logre la Corte Suprema.

Todo esto muestra que no existe una cultura judicial tendiente a respetar las interpretaciones contenidas en las decisiones pronunciadas por la Corte Suprema en unificación de jurisprudencia. La consecuencia es un potente golpe en contra del cumplimiento de los objetivos de dicho recurso. Y, por lo mismo, un obstáculo al logro de varias de las ventajas asociadas a la existencia del mismo y que fueran más arriba reseńadas.

\section{(2.3) RECHAZO DOCTRINARIO A LA IDEA DE UNIFICAR LA JURISPRU- DENCIA}

Un tercer problema con el que se verá enfrentada la unificación de jurisprudencia pretendida por el recurso extraordinario se refiere a la existencia de una consciente opinión doctrinaria que se opone a entregar a la Corte Suprema la facultad de unificar la jurisprudencia. En este caso no se trata de una opinión exclusivamente sostenida en Chile, sino también entre autores de otras latitudes, y con argumentos de diverso calado.

49 Bordalí Salamanca, Andrés (2009). "El derecho fundamental a un tribunal independiente e imparcial en el ordenamiento jurídico chileno”. Revista de Derecho de la Pontificia Universidad Católica de Valparaíso, No 33, p. 281. 


\section{(2.3.1) La falta de independencia judicial}

En este sentido, una primera objeción a la unificación de jurisprudencia se encuentra en la independencia judicial. En lo esencial, este argumento sostiene que el sometimiento a las interpretaciones de la Corte Suprema atenta contra la independencia con que deben contar los tribunales para resolver los casos entregados a su decisión ${ }^{50}$. En este sentido se pronuncia categóricamente Herrera cuando afirma: "Los jueces inferiores no están sujetos a instrucciones, ni líneas, ni actuan en forma dirigida, ni mecánica a las directrices, pues el juez solo está sometido a la ley y a su conciencia, no está obligado a acatar la decisión de la Corte Suprema"51. En el mismo sentido se pronuncian, por ejemplo, Remón ${ }^{52}$ y Ramírez ${ }^{53}$. Incluso advierten sobre esta colisión de intereses entre independencia judicial y sumisión a las interpretaciones de la Corte Suprema algunos partidarios de la sumisión a las interpretaciones del Derecho formuladas por la Corte Suprema, como Castillo Alva ${ }^{54}$ y García Toma ${ }^{55}$.

50 Debe destacarse que en el Derecho español la independencia de los tribunales es una garantía de jerarquía constitucional, como expresamente lo dispone el artículo 117.1 de la Constitución: "La justicia emana del pueblo y se administra en nombre del Rey por Jueces y Magistrados integrantes del poder judicial, independientes, inamovibles, responsables y sometidos unicamente al imperio de la ley".

51 Herrera Carbuccia, Manuel Ramón (2006). "Importancia de la Unidad de la Jurisprudencia Laboral, Análisis y Discusión”. Gaceta Laboral, vol. 12, No 1. Disponible en: http:// www.scielo.org.ve/scielo.php?...85972006000100006 [fecha de visita 7 Mayo 2009], pp. 123-142, p. 134.

52 Categóricamente afirma Remón (2009): "La independencia judicial, clave de bóveda del Estado de Derecho, se convierte de este modo en un obstáculo para la conformación de un sistema de sujeción automática al precedente. La independencia equivale a ausencia de subordinación (DE OTTO) y supone que, en el ejercicio de su función, los jueces no están sujetos a órdenes ni instrucciones de nadie".

53 Al respecto expresa Ramírez, José Antonio (2009). "La rebelión de los jueces. La jurisprudencia es vinculante para el juez?". Disponible en: http://www.pensamientopenal.com. ar/36ramirez.rtf [fecha de visita 6 febrero 2009] p. 9: "El conflicto se presenta entre dos valores: la uniformidad de la jurisprudencia vs. la independencia del juzgador".

54 Sobre el punto expresa Castillo (2009) p. 40: "Por otra parte, el juez no puede ni debe aceptar acriticamente el precedente. Asi lo impone la independencia judicial 221, la exclusiva obligación de vincularse a la Constitución y a la ley y la necesaria separación de poderes en la función de creación y aplicación de las normas". Como se puede advertir, el autor admite la sumisión al precedente, pero entiende que este puede no ser seguido si así lo dispone el principio de independencia judicial.

55 Como destaca García (2009), en el Derecho constitucional peruano existe el mandato de sumisión al precedente vinculante. Así lo estatuye expresamente el artículo VII del título preliminar del Código Procesal Constitucional. Pues bien, el autor afirma, p. 401, que dicha sumisión "deviene en un limite al principio de independencia judicial establecido en el inciso 2 del artículo 139 de la Constitución [peruana]". 


\section{(2.3.2) La petrificación del Derecho}

Una segunda objeción a la unificación de jurisprudencia se refiere a que impide la evolución del Derecho. De acuerdo con esta perspectiva, dicha sumisión petrifica o rigidiza el ordenamiento jurídico. En este sentido se pronuncia Nieva, para quien "la riqueza del ordenamiento se basa, entre otros puntos, en que el Derecho no fosilice sus interpretaciones $y$, por tanto, en que la jurisprudencia no permanezca estática". De ahí que el autor añada, refiriéndose a las decisiones judiciales, que "algo que debería ser mucho más ágil, dinámico y adaptable que una ley, se torna estático, lento, inamovible y anquilosado" 56 . En igual dirección se pronuncia Herrera cuando expresa: "El precedente judicial es un tanto persuasivo, pero no favorece en su aplicación mecánica y literal a una jurisprudencia más reflexiva, más lógica, más critica, lo cual no quiere decir ni pretender crear situaciones impropias en el aparato judicial, pero si asegurar la independencia de los jueces" 57 .

Resulta ineludible reconocer que de algún modo esta segunda objeción se encuentra aparentemente resuelta en el proyecto de Código Procesal Civil, al establecer entre las causales del recurso extraordinario el que nuevos contextos históricos, sociales o culturales justifiquen variar la tendencia jurisprudencial ${ }^{58}$. Sin embargo, esta solución abre la puerta a un nuevo problema, pues la existencia de esta causal permitiría cuestionar reiteradamente las interpretaciones sostenidas por el máximo tribunal. En este sentido se pronunció la Corte Suprema al emitir su opinión respecto del proyecto de Código Procesal Civil. Al respecto advirtió que con esta causal se da al recurso extraordinario "una amplitud tal que dejaría de ser extraordinario para transformarse en un medio corriente de impugnación de sentencias que se han ajustado a un criterio sostenido y uniforme en la interpretación de la ley, aplicándose al asunto controvertido" 59.

56 Y con singular énfasis añade Nieva Fenoll, Jordi (2006). "La reforma de la labor del Tribunal Supremo y la unificación de doctrina. Perspectivas de la introducción del modelo anglosajón en nuestro Derecho". Diario La Ley, No 6393, Sección Doctrina, año XXVII, Editorial La Ley, p. 2: "Porque si el valor principal es conservar la jurisprudencia, el ordenamiento jurídico positivo no acaba siendo más que un pretexto para construir esa jurisprudencia. $Y$ mientras no es reformado, la jurisprudencia continúa siendo la misma, porque, evidentemente, humanamente es mucho más cómodo y sencillo mantenerla que modificarla, teniendo que justificar por qué. Finalmente, el Tribunal Supremo se acaba convirtiendo en un órgano de inadmisión de recursos, asi como de conservación de la jurisprudencia como si de una reliquia se tratase. $Y$ el ordenamiento juridico se queda sin su principal acicate: el Tribunal Supremo". Herrera (2006) p. 134.

Artículo 354, letra d), del proyecto de Código Procesal Civil.

Oficio $\mathrm{N}^{\circ} 199$, de 7 de agosto de 2009, remitido por la Corte Suprema al Senado, en el que informa su parecer respecto del proyecto de ley que contiene el nuevo Código Procesal Civil. 


\section{(2.3.3) El impredecible juicio de igualdad}

Una de las condiciones de aplicación de la unificación de jurisprudencia es que los hechos del caso actual sean iguales a los hechos del caso precedente. Pues bien, una tercera objeción a la unificación de jurisprudencia pretendida por el recurso extraordinario consiste en la imposibilidad de contar con unívocos juicios de igualdad. Esta dificultad es mencionada por Couso y Mera, quienes atienden al carácter valorativo del juicio de igualdad. De acuerdo con estos autores, "la práctica de seguimiento de precedentes [unificación de jurisprudencia, se diría aquí] es de contornos difusos, en la medida que la aplicación del precedente al caso actual está sujeta a un momento valorativo, que se da caso a caso, consistente en examinar si hay una semejanza relevante entre el caso precedente y el actual que justifique aplicar a este una regla que fue decisoria del caso precedente" 60.

De acuerdo con lo recién explicado, la unificación de jurisprudencia no hace más que reconducir la indeterminación de los enunciados normativos y de las normas expresadas en ellos a un impredecible juicio de igualdad. En efecto, la unificación de jurisprudencia es una aplicación del mandato trata igual a lo igual y desigual a lo desigual, específicamente en el ámbito jurisdiccional. Sin embargo, para poder aplicarlo, frente a cada caso sería necesario determinar si sus hechos coinciden con los hechos de un caso anteriormente resuelto por la Corte Suprema, pues solo así se sabría si se trata de casos iguales o desiguales.

De este modo, podría ocurrir que la Corte Suprema entienda que no son relevantes las diferencias que puedan existir entre los casos y persiga la unidad de la interpretación en las normas ante supuestos desiguales. $\mathrm{O}$ bien pudiera ser que confundiera igualdad con identidad ${ }^{61}$, de modo que llevase al recurso a resultar además de extraordinario, excepcional ${ }^{62}$. Cualquiera de las dos situaciones es posible debido a que, como se sabe, el concepto de igualdad es esencialmente valorativo y la valoración debe ser realizada por el juzgador.

60 Couso, Jaime y Mera, Jorge (2007). "El Rol Uniformador de la Jurisprudencia de la Sala Penal de la Corte Suprema: Estudio empírico". Ius et Praxis, vol. 13, No 1. Disponible en: http://www.scielo.cl/pdf/revider/v20n2/art07.pdf [fecha de visita 7 mayo 2009].

61 Para una correcta inteligencia de la diferencia entre los conceptos identidad e igualdad, véase Comanducci, Paolo (1999). "Igualdad liberal". Revista Jurídica de la Universidad de Palermo, No 2, año 3, p. 84.

62 Tomando un ejemplo de la doctrina extranjera, Molero Marañón, María Luisa (1997). El Recurso de Casación para la Unificación de Doctrina en la Jurisdicción Social. Valladolid: Lex Nova, p. 106, considera un supuesto excepcional (vgr., el caso de la sentencia del Tribunal Supremo español de 6 de febrero de 1992 (Art. 920) en la que se aportaba por el recurrente una sentencia, en la que el mismo actor y contra la misma empresa que en la recurrida, reclamaba el mismo concepto salarial, por períodos distintos. Ambos casos, resueltos por el mismo Tribunal Superior de Justicia, llegaron a pronunciamientos contradictorios. 


\section{(2.3.4) ¿Búsqueda de la igualdad en la aplicación de la ley?}

Los recursos que abogan por la unificación de jurisprudencia tienden a contemplar como finalidad la consecución de la igualdad en la aplicación de la ley. Ahora bien, este objetivo no se observa de una forma directa en el recurso extraordinario. No existe como objeto directo la salvaguarda del derecho fundamental a la igualdad. Al menos no se desprende así del texto del Proyecto, puesto que no se contempla ninguna previsión que así nos lo haga entender. Sin embargo, debemos reconocer que, a lo menos de forma indirecta, debería contribuir a la consecución de una mejor protección de la igualdad.

Las causales por las que se puede interponer el recurso, recogidas en el artículo 354 del Proyecto de Código Procesal Civil, han sido diseñadas al modo de los sistemas anglosajones ${ }^{63}$. En atención, especialmente, a las dos primeras causales podemos afirmar que esta pretendida defensa del derecho fundamental a la igualdad no es, en realidad, la última finalidad que persigue el legislador. El recurso tiene por objetivo cierto la búsqueda de una jurisprudencia uniforme, hecho que incidirá en la consecución de la igualdad en la aplicación de la ley, pero el legislador no contempló expresamente esta previsión en el texto legal. Además, en la práctica podremos ver como la jurisprudencia podrá ser igual, pero no necesariamente se van a establecer las distinciones necesarias que cada caso particular merezca.

\section{(2.3.5) Seguridad jurídica restringida}

Un quinto problema en el diseño del recurso extraordinario consiste en que no todos los casos llegarán a conocimiento de la Corte Suprema, debido a las restricciones que se han diseñado al efecto. Esto también redundará en una menor consecución de la aplicación de los principios de igualdad y seguridad jurídica.

63 Así por ejemplo, la Rule 10 de la Supreme Court Rules de los Estados Unidos permite la interposición del writ of certiorari en tres supuestos: “(a) a United States court of appeals has entered a decision in conflict with the decision of another United States court of appeals on the same important matter; has decided an important federal question in a way that conflicts with a decision by a state court of last resort; or has so far departed from the accepted and usual course of judicial proceedings, or sanctioned such a departure by a lower court, as to call for an exercise of this Court's supervisory power; (b) a state court of last resort has decided an important federal question in a way that conflicts with the decision of another state court of last resort or of a United States court of appeals; (c) a state court or a United States court of appeals has decided an important question of federal law that has not been, but should be, settled by this Court, or has decided an important federal question in a way that conflicts with relevant decisions of this Court". 
En efecto, la Corte Suprema, según la prescripción normativa, cumple con seleccionar aquellos supuestos que, cumpliendo con todos los requisitos, presentan interés público ${ }^{64}$. Pues bien, será muy difícil que un caso en que se discute Derecho privado alcance relevancia pública ${ }^{65}$, de modo que la seguridad jurídica se va a ver comprometida, desde el momento en que la Corte comience a funcionar con una lógica economicista en la selección de sus asuntos. El (ab)uso de una potestad discrecional de selección de asuntos puede orientar la actuación de la Corte Suprema hacía la consecución de unos datos estadísticos engañosos en que consigue índices de resolución muy rápidos, en base a la inadmisión sistemática de todo tipo de asuntos.

El problema concreto al hablar de la selección discrecional de asuntos es, precisamente, el poder que se le otorga al órgano jurisdiccional y sus lindes respecto a lo que se pueda considerar arbitrariedad. La doctrina es suficientemente uniforme en afirmar que la Corte Suprema no constituye una tercera instancia ${ }^{66}$. No todos los asuntos pueden llegar al conocimiento del máximo intérprete jurisdiccional; sin embargo, un cambio como el propuesto va a crear una situación paradójica: por una parte, la uniformidad de la jurisprudencia consigue una mayor seguridad jurídica -en el sentido visto de certeza o predictibilidad- y, por otra parte, el entregar un mecanismo de selección discrecional fundado en interés público crea justo lo contrario. No sería justo llamarlo inseguridad jurídica, pero sí incertidumbre discrecional. De este modo se pueden perder las mejores cabezas de nuestra judicatura, precisamente las que deberían proyectar un alto grado de seguridad en la actuación de la Corte Suprema.

\section{(2.3.6) El quiebre del sistema de fuentes de la familia europeo- continental}

Una sexta y última objeción se refiere a que la unificación de jurisprudencia se opone al sistema de fuentes de la familia jurídica europeo-continental. Al respecto, parece posible afirmar que, empíricamente hablando, en dicho entorno jurídico cultural se rechaza otorgar a la jurisprudencia el carácter de fuente del Derecho. La adopción de esta perspectiva puede tener justificaciones ideológicas o simplemente culturales. Así, y desde un plano ideológico, admitir que las decisiones judiciales tienen fuerza nor-

64 Delgado Castro, Jordi (2010). "El certioriari: Un agente extraño en manos de nuestra Corte Suprema”. Actualidad Jurídica, Universidad del Desarrollo, No 22, p. 366.

65 Palomo Vélez, Diego (2005). "Proceso civil oral: ¿Qué modelo de juez requiere?". Revista de Derecho, Universidad Austral de Chile, No 18, pp. 175 y ss.

66 La doctrina nacional ha venido entendiéndolo así desde antiguo: ANABALón SANDERson, Carlos (1946). Tratado práctico de derecho procesal civil chileno. Santiago: Ediciones de la Universidad de Chile, p. 267. 
mativa provocaría la confusión de funciones del Estado y, según sostiene algún autor, incluso conllevaría la destrucción del estado de Derecho ${ }^{67}$. Desde una perspectiva cultural, muchos juristas se niegan a abandonar la concepción tradicional del juez como mero aplicador del Derecho ${ }^{68}$. En cualquiera de los dos casos se trata de una consciente oposición a la unificación de jurisprudencia pretendida por el recurso extraordinario.

\section{(2.4) El PROBlema de la FUNCIÓN DE LA CORTE SUPREMA}

Finalmente, debemos señalar que el diseño del nuevo medio de impugnación también ha generado cuestionamientos por parte de la Corte Suprema. Muy significativamente la Corte ha señalado que "en la presente reforma podría unificarse la función de la Corte Suprema entregándole en todos los procesos el conocimiento de un mismo recurso de nulidad o casación que pueda basarse en la infracción de la ley cometida en el fallo impugnado"69.

Efectivamente, con buen criterio el Alto Tribunal considera necesario que su función sea uniforme y homogénea en todos los ámbitos de actuación. En realidad, las grandes reformas procesales del país han ido avanzando en líneas similares con las particularidades propias de cada orden. Sin embargo, se está dejando para el final el procedimiento supletorio y común a todos los demás. Así, se están creando distintos sistemas de impugnación y se está generando una pluralidad de funciones en manos de nuestra Corte Suprema.

67 En este sentido, y al menos en lo que se refiere a la interpretación constitucional, TAMAYO Jaramillo, Javier (2009). "Hermenéutica constitucional y legal. Al rescate de la pureza del Derecho". Disponible en: http://www.eleccionvisible.com/doc/ternas/CSJ/T1_JTJ/T1_JTJ_ LIBRO.pdf [fecha de visita 10 mayo 2009], p. 1, sostiene que "el Estado de Derecho desaparece en aquellos paises donde el activismo de la Corte Constitucional y de los jueces los autoriza para arrogarse el derecho de legislar y desconocer las normas legales y constitucionales al vaivén de las concepciones ideológicas de sus magistrados". Esta afirmación podría resultar aplicable, en alguna medida, al ámbito del Derecho infraconstitucional y específicamente al Derecho civil.

68 Al respecto, afirma Pilonieta Pinilla, Eduardo (2007). "Obligatoriedad del precedente jurisprudencial en el sistema jurídico colombiano". Disponible en: http://www.acj.org.co/ activ_acad.php?mod=posesion\%20pilonieta\%20pinilla [fecha de visita 10 mayo 2009], que "en la actualidad muchos juristas se niegan a abandonar el imaginario que limita al Juez como un simple instrumentador de la ley y a la jurisprudencia como un criterio auxiliar que no lo obliga necesariamente al momento de decidir sobre un asunto en particular". En igual sentido HeIsse (2009) p. 3, advierte que probablemente "la primera impresión que provoque evocar tal término [precedente] dentro de nuestra cultura jurídica será de reticencia, hemos sido formados como juristas bajo la creencia de que nuestro sistema legal excluye "per se" el efecto general $y$ vinculante de las decisiones anteriores de los tribunales de justicia fundamentado entre otros motivos por ser los precedentes propios de los sistemas del common law y por la exclusión explicita señalada en nuestro Código Civil". Aunque este último autor alude a la noción de "precedente", lo dicho resulta perfectamente aplicable a la unificación de jurisprudencia. 
Es cierto que la especialización procedimental puede llevar a establecer aquellas diferencias que son necesarias en cada faceta del ordenamiento jurídico. Por ejemplo, el proceso laboral debe tutelar especialmente los derechos del trabajador y el proceso penal debe conciliar el esclarecimiento de los hechos con la defensa de los derechos fundamentales del imputado. Sin embargo, no parece conveniente desde el punto de vista de la técnica legislativa ni de un más adecuado funcionamiento del Poder Judicial que cada área del Derecho cuente con un sistema recursivo singular para ante la Corte Suprema. Es lo que en este momento estaría ocurriendo si se considera que en la justicia de familia se aplica la casación en el fondo, en la justicia penal el recurso de nulidad, en la justicia laboral el recurso de unificación de jurisprudencia y en la justicia civil el recurso extraordinario.

En este sentido, no es difícil coincidir con la demanda de la Corte Suprema consistente en que se necesita un órgano que desde la cúspide dé sentido a todo el sistema con un criterio único. Esto implica una decisión política y jurídica consensuada respecto de cuál debe ser la función de la Corte Suprema. Al respecto, parece posible sostener que la función del máximo intérprete pasa por algo más allá que uniformar jurisprudencia (que también es una de sus misiones). Junto con ello, su función ha de ser defender la correcta aplicación de la ley, coincidiendo con la misión del recurso de casación en el fondo que, históricamente, determinó la creación de un tribunal con vocación de mantener y cuidar la observancia de la ley ${ }^{70}$.

\section{(2.5) TÉCNICA LEGISLATIVA}

Las críticas señaladas dan cuenta de posturas doctrinales más o menos consolidadas en el foro y que resultan de aplicación al recurso extraordinario. En este momento se explicará un problema derivado, concretamente, de la letra de la ley que, aunque no se refiere estrictamente a razones por las cuales el recurso extraordinario podría no cumplir sus objetivos, se conecta con lo anteriormente significado.

El proyecto de Código Procesal Civil ${ }^{71}$ señala que la función de la Corte Suprema es preservar la coherencia y unidad de los principios por

70 VÁsquez Sotelo, José Luis (1993) "El modelo español de casación (Configuración histórica y evolución legislativa)" En Scritti in onore di Elio Fazzalari. Milano: Giuffrè Editore, p. 357. "Art. 354. Unificación de la Jurisprudencia. La función de la Corte Suprema es preservar la coherencia y unidad de los criterios de decisión en los tribunales del pais en virtud del recurso extraordinario. En consecuencia, ejercerá su función de unificación cuando:

a) La sentencia recurrida se oponga a la jurisprudencia uniforme.

b) La jurisprudencia previa fuere contradictoria entre sí.

c) No existiere jurisprudencia sobre la materia.

d) Nuevos contextos históricos, sociales o culturales justifiquen variar la tendencia jurisprudencial." 
los que los tribunales adoptan sus pronunciamientos. Si bien es cierto que una de las funciones que desempeña la Corte mediante la resolución del recurso de casación es la preservación de los criterios de decisión de los tribunales del país, no es la única. La revisión de los textos legales así lo muestran: así la Constitución Política de la República otorga funciones a la Corte Suprema en distintos artículos (por ejemplo, art. 12, art. 19, 7o, i)...) resultando especialmente oportuna la previsión del artículo 77 que indica expresamente que una ley orgánica constitucional se encargará de establecer la organización y atribuciones de los tribunales.

De modo que las funciones de la Corte Suprema deberían contemplarse en el Código Orgánico de Tribunales. De hecho, ahora mismo el COT regula claramente las funciones de la Corte Suprema en sus artículos 93 y siguientes. Por lo tanto, la indicación que recoge el artículo 354 del proyecto parece a lo menos discutible por establecerse funciones de la Corte en un cuerpo legislativo distinto al ideal.

Seguramente se encuentran funciones propias de la Corte Suprema en el diseño del recurso de casación en el fondo, pero también es cierto que ha de ser misión de la doctrina destacar aquellas peticiones que de lege ferenda serían totalmente deseables. Quizá parte de la problemática que pueda levantar, en general, la reforma procesal civil pasa por una revisión conjunta del Código Orgánico de Tribunales que debiera modernizarse y sintonizarse con todas las reformas ya acometidas. Sería un proyecto más ambicioso, pero de buen seguro daría coherencia a todo el sistema.

\section{CONCLUSIONES}

La redacción de este trabajo de investigación y aproximación al recurso extraordinario nos ha dejado dos grandes conclusiones que derivan en una pregunta. En primer lugar, se ha mostrado que existen ventajas relevantes derivadas de la unificación de jurisprudencia. Además, se ha evidenciado también que existen problemas relevantes relacionados con el estilo tradicional de entender el modelo de justicia. En consecuencia, es necesario evaluar si se pueden aplicar correcciones normativas o institucionales tendientes a asegurar el cumplimiento de la unificación de jurisprudencia pretendida por el recurso extraordinario.

Es indudable que un mecanismo como el recurso extraordinario trae consigo muchas ventajas. En especial, hemos destacado varias que son muy significativas: la igualdad en la aplicación de la ley y el incremento de la seguridad jurídica son valores reconocidos universalmente como deseables para todo ordenamiento jurídico y nuestra Constitución, así como las de nuestro entorno jurídico cultural propenden a buscar y defender la promoción de los mismos. 
Señalamos, además, otra serie de utilidades prácticas como la simplificación de la labor interpretativa de los tribunales, el aumento en la confianza en el sistema y la atenuación de la intervención de elementos extrajurídicos en las resoluciones judiciales. E, incluso, observamos algunos méritos de carácter más bien económico como el descenso de la litigiosidad o la previsión de los costos del proceso civil.

En lo que no reparamos, de forma intencionada con el objetivo de analizar lo más asépticamente el medio impugnatorio, fue en señalar que la principal ventaja que tiene este recurso es que se ajusta plenamente al diseño del sistema recursivo. No quisimos entrar en el análisis detallado de todo el sistema, para poder observar despojado de otros elementos este original medio de impugnación. Sin embargo, entendemos que el recurso extraordinario es la consecuencia lógica del nuevo diseño de recursos del proceso civil ${ }^{72}$. Efectivamente, un modelo que aboga por un juez empoderado ha de restringir las sucesivas correcciones y debería limitar el acceso de asuntos al conocimiento de la Corte Suprema. Ahora bien, el objetivo de este trabajo era significar cuáles son las ventajas derivadas de este modelo independientemente de la "perfección" del sistema en sí mismo.

Precisamente, esa observación neutra sin tener en cuenta el conjunto sino el instrumento propiamente, nos ha permitido destacar los mayores inconvenientes que, a la luz de la experiencia del recurso de unificación de jurisprudencia junto a algún elemento de Derecho comparado, tiene el recurso extraordinario. El primero de ellos se refiere a la concepción prevaleciente respecto del efecto relativo de las sentencias. El segundo consiste en la inexistencia de una cultura judicial tendiente a respetar las interpretaciones de la Corte Suprema. El tercero es el rechazo que presenta parte importante de la doctrina a la idea de unificar la jurisprudencia. Por último, el recurso extraordinario pone en evidencia un problema político y jurídico relativo a la función de la Corte Suprema.

Nos restaría por destacar que la realización material de este estudio ha sido posible por la necesidad de los autores de buscar una aproximación científica y neutra al recurso extraordinario. Partiendo de posiciones diametralmente opuestas respecto de la conveniencia y necesidad del recurso extraordinario, hemos conseguido, esperamos que a juicio del lector, destacar las consecuencias favorables más importantes derivadas de la

72 En especial, resulta muy interesante la afirmación que uno de los actores de la reforma realiza: Núñez OJedA, Raúl (2008). "El sistema de recursos procesales en el ámbito civil en un Estado Democrático Deliberativo". Revista Ius et Praxis, No 14, p. 223: "Un sistema de impugnación en un Estado democrático deliberativo debe respetar este binomio. Si fortalecemos los poderes del juez de instancia y confiamos en los mismos, necesariamente debemos reducir el nivel impugnación de las sentencias definitivas a niveles racionales. Impugnación que necesariamente pasa por respetar la función jurisdiccional y estructura del nuevo sistema procesal civil'. 
adopción de este original medio de impugnación, así como anticipar los posibles problemas que se presentarán en orden a lograr los objetivos pretendidos por el mismo.

\section{BIBLIOGRAFÍA CITADA}

Alessandri Rodríguez, Arturo et al. (2005). Tratado de Derecho Civil. Santiago: Editorial Jurídica de Chile.

Anabalón Sanderson, Carlos (1946). Tratado práctico de derecho procesal civil chileno. Santiago: Ediciones de la Universidad de Chile.

Bordalí Salamanca, Andrés (2009). "El derecho fundamental a un tribunal independiente e imparcial en el ordenamiento jurídico chileno". Revista de Derecho de la Pontificia Universidad Católica de Valparaiso, No 33.

Castillo Alva, José Luis (2009). "El uso de los precedentes judiciales como técnica de argumentación racional. Su alcance y valor en el Derecho peruano". Disponible en: http://www.unifr.ch/ddp1/ derechopenal/articulos/a_20080521_46.pdf [fecha de visita 6 febrero 2009], p. 5, sostiene que la ventaja del uso del precedente se encuentra, entre otros motivos, en la "realización del principio de igualdad".

Claro Solar, Luis (1992). Explicaciones de Derecho civil chileno y comparado. Santiago: Editorial Jurídica de Chile.

Colombo Campbell, Juan (1997). Los actos procesales. Santiago: Editorial Jurídica de Chile.

Comanducci, Paolo (1999). "Igualdad liberal". Revista Jurídica de la Universidad de Palermo, No 2, año 3.

Couso, Jaime y Mera, Jorge (2007). "El Rol Uniformador de la Jurisprudencia de la Sala Penal de la Corte Suprema: Estudio empírico". Ius et Praxis, vol. 13, No 1. Disponible en: http://www. scielo.cl/pdf/revider/v20n2/art07.pdf [fecha de visita 7 mayo 2009].

De Asís Roig, Rafael (1995). Jueces y normas. La decisión judicial desde el ordenamiento. Madrid: Marcial Pons, 1995.

De Asís Roig, Rafael (1999). "Breves reflexiones sobre los valores y los derechos en la Constitución Española en su veinte aniversario". Revista de Derecho Constitucional, El Salvador, 1999, N³3, vol. T. 1. Disponible en: http://www.csj.gob.sv/Doctrina.nsf/5a638ba98cb 9b7ea86256d47004bac46/b90b821702451afe0625694d00527df4 ?OpenDocument [fecha de visita 11 noviembre 2008].

Delgado Castro, Jordi (2009). "La historia de la casación civil espańola: una experiencia que aconseja no avanzar en el modelo de unificación de la doctrina". Revista de Derecho de la Pontificia Universidad Católica de Valparaíso, XXXIII. 
Delgado Castro, Jordi (2010). "El certioriari: Un agente extraño en manos de nuestra Corte Suprema”. Actualidad Jurídica, Universidad del Desarrollo, No 22.

Ducci Claro, Carlos (2002). Derecho civil. Parte general. Santiago: Editorial Jurídica de Chile.

Figueroa García-Huidobro, Rodolfo (2008) "Igualdad y discriminación”. Disponible en derechoshumanos.udp.cl/wpcontent/uploads/2009/07/ihualdad-y-no-discrim.pdf, en línea, [fecha de visita 22 julio 2008].

Figueroa Yáñez, Gonzalo (1992). Curso de Derecho Civil. Santiago: Editorial Jurídica de Chile.

García Toma, Víctor (2009). "Las sentencias: conceptualización y desarrollo jurisprudencial en el Tribunal Constitucional peruano". En Ferrer Mac-Gregor, Eduardo y Zaldívar Lelo de Larrea, Arturo, (coordinadores) La Ciencia del Derecho procesal constitucional. Estudios en homenaje a Héctor Fix-Zamudio en sus cincuenta años como investigador del Derecho, T. V. juez y sentencia constitucional. Disponible en: http://www.incipp.org.pe/modulos/documentos/ descargar.php?id=231 [fecha de visita 9 febrero 2009].

García, José Francisco (2007). "Reforma al Poder Judicial: una agenda para la discusión". Serie Informe Politico, Libertad y Desarrollo, No 100. Disponible en: http://www.ild.cl/biblioteca/serie/politico/88_ serie_informe_politico.pdf [fecha de visita 14 febrero 2009].

Heisse Burgos, Gustavo (2009). "Reflexiones en torno a la Jurisprudencia y el precedente judicial en la cultura jurídica chilena”. Disponible en: http://www.jornadasderechopublico.ucv.cl/.../ Reflexiones\%20en\%20torno\%20a\%20la\%20Jurisprudencia\%20y... [fecha de visita 10 mayo 2009].

Hernández Martínez, María del Pilar (1994). "El principio de igualdad en la jurisprudencia del Tribunal Constitucional español (Como valor y como principio en la aplicación jurisdiccional de la ley)". Boletín Mexicano de Derecho Comparado, Año XXVII, N 81, sep.dic. Disponible en: http://www.juridicas.unam.mx/publica/rev/ boletin/cont/81/art/art4.htm [fecha de visita 10 mayo 2009]

Herrera Carbuccia, Manuel Ramón (2006). "Importancia de la Unidad de la Jurisprudencia Laboral, Análisis y Discusión”. Gaceta Laboral, vol. 12, No 1. Disponible en: http://www.scielo.org.ve/ scielo.php?...85972006000100006 [fecha de visita 7 Mayo 2009]

Larraín Ríos, Hernán (2004) Lecciones de Derecho Civil. Santiago: Editorial Jurídica de Chile.

Linares, Sebastián (2004). "Política y gobierno". Vol. XI, N¹, primer semestre. Disponible en: http://www.politicaygobierno.cide. edu/.../Sebastian_Linares_p-73-126.pdf [fecha de visita 10 mayo 2009] 
Magro Servet, Vicente (2007). "La unificación de criterios: una anhelada aspiración”. Diario La Ley, No 6498, Sección Doctrina, año XXVII, Editorial La Ley

Magro Servet, Vicente (2008). "Hacia un régimen de consultas de las Audiencias Provinciales y Tribunales Superiores de Justicia al Tribunal Supremo para unificación de doctrina”. Diario La Ley, No 7047, Sección Doctrina, año XXIX, Editorial La Ley

Molero Marañón, María Luisa (1997). El Recurso de Casación para la Unificación de Doctrina en la Jurisdicción Social. Valladolid: Lex Nova.

Moreno Ortiz, Luis Javier (2009). "¿Hacia un sistema jurídico sin precedentes?”. Disponible en: http://www.usergioarboleda.edu.co/ derecho/haciaunsistemajuridicodepresedentes.html [fecha de visita10 mayo 2009]

Nieva Fenoll, Jordi (2006). "La reforma de la labor del Tribunal Supremo y la unificación de doctrina. Perspectivas de la introducción del modelo anglosajón en nuestro Derecho”. Diario La Ley, No 6393, Sección Doctrina, año XXVII, Editorial La Ley.

Núñez OjedA, Raúl (2008). "El sistema de recursos procesales en el ámbito civil en un Estado Democrático Deliberativo". Revista Ius et Praxis, No 14.

Palomo Belén, Diego (2005). "Proceso civil oral: ¿Qué modelo de juez requiere?". Revista de Derecho, Universidad Austral de Chile, No 18.

Parra, María Victoria (2004). "El precedente judicial en el Derecho comparado". Criterio Juridico, No 4. Disponible en: http:// criteriojuridico.puj.edu.co/.../10_239_mvparra_precedente_judicial. pdf [fecha de visita 13 febrero 2009].

Peces-Barba Martínez, Gregorio (1999). Curso de derechos fundamentales. Madrid: Universidad Carlos III de Madrid y Boletín Oficial del Estado.

Pilonieta Pinilla, Eduardo (2007). "Obligatoriedad del precedente jurisprudencial en el sistema jurídico colombiano". Disponible en: http://www.acj.org.co/activ_acad.php? $\bmod =\operatorname{posesion} \% 20$ pilonieta\%20pinilla [fecha de visita 10 mayo 2009].

Ramírez, José Antonio (2009). "La rebelión de los jueces. La jurisprudencia es vinculante para el juez?”. Disponible en: http:// www.pensamientopenal.com.ar/36ramirez.rtf [fecha de visita 6 febrero 2009].

Remón Peñalver, Jesús (2007). "La lucha por la seguridad jurídica". Disponible en: http:// www.clubarbitraje.com/files/docs/libro_ fusion.pdf [fecha de visita 23 febrero 2009].

Tamayo Jaramillo, Javier (2009). "Hermenéutica constitucional y legal. Al rescate de la pureza del Derecho". Disponible en: http://www. eleccionvisible.com/doc/ternas/CSJ/T1_JTJ/T1_JTJ_LIBRO.pdf [fecha de visita 10 mayo 2009]. 
VÁsquez Sotelo, José Luis (1993) "El modelo español de casación (Configuración histórica y evolución legislativa)" En Scritti in onore di Elio Fazzalari. Milano: Giuffrè Editore. 